\title{
RÚSSIA, CHINA E A COREIA DO SUL NO MERCADO DE DEFESA SUL-AMERICANO
}

\section{Ricardo Borges Gama Neto ${ }^{1}$}

\section{Introdução}

Este artigo trabalha com dois temas interligados. O primeiro é a relação entre ideologia política e compra de armamentos de defesa e o segundo a abertura do mercado, ocorrido nos últimos anos na América do Sul. As fortes mudanças na economia e política do subcontinente, ocorridas a partir do final do século passado e as primeiras décadas deste, trouxeram impactos profundos, não apenas no ambiente político, mas também nas compras de equipamentos de defesa. Mudanças políticas em países chaves como Venezuela, Argentina, Bolívia e Brasil e o crescimento das economias a partir do boom de commodities impulsionaram a compra de materiais de defesa ao mesmo tempo que abria o mercado para novos vendedores. A Rússia como descendente da União Soviética manteve seus restritos compradores, e com o fim da guerra fria passa a ampliar seu mercado ao vender equipamentos que eram vetados pela política norte-americana, como por exemplo mísseis BVR Vympel R-77 e mísseis do tipo MANPAD Igla.

Outros importantes fornecedores de materiais de defesa têm adentrado no mercado sul-americano. Certamente, os mais importantes são China e a Coreia do Sul. O primeiro utiliza de seu potencial de negociação econômica e política, adquirido no período de forte crescimento econômico e de aumento das relações comerciais, para adentrar no mercado tanto da Rússia quanto de outros países. O portfolio chinês é extenso e vai de canhões a jatos de treinamento. Outra importante arma chinesa é a capacidade dos bancos estatais chineses de financiarem estas compras. A Coreia do Sul tenta adentrar no

\footnotetext{
I Professor do departamento de Ciência Política da Universidade Federal de Pernambuco (UFPE). Pesquisa temas nas áreas de Política Comparada, Metologia Quantitativa, Computação Aplicada à Ciência Política e Estudos de Defesa. Foi diretor de Pesquisa da Associação Brasileira de Ciência Política (ABCP) e é professor dos programas de pós-graduação em Ciência Política da UFPE e Ciências Militares da ECEME.
} 
mercado, utilizando estratégias comerciais agressivas e sistemas de armas de alta tecnologia como aviões e mísseis.

$\mathrm{O}$ artigo se vale de bibliografia especializada e de banco de dados de estatística da Comissão Econômica para a América Latina e Caribe (CEPALSTAT) $^{2}$ e do registro de comércio de armas Stockholm International Peace Research Institute (SIPRI) ${ }^{3}$, que contêm dados oficiais de compradores e vendedores de armamento do mundo.

O artigo está composto por esta introdução, o desenvolvimento em dois capítulos e uma conclusão.

\section{América do Sul, Transformações Econômicas e Políticas do Início do Século XXI}

O processo de redemocratização, que aconteceu na América Latina durante as décadas de I980 e I990, ocorreu conjuntamente com uma forte e persistente crise econômica, marcada principalmente por altas taxas de inflação e profundo endividamento público. Os desajustes que as economias latino-americanas apresentaram foi consequência, principalmente, do aumento das dívidas públicas na década anterior e da violenta expansão dos encargos financeiros, derivados da elevação das taxas de juros internacionais. Nos anos I970, durante e após a primeira crise do petróleo, quando os países centrais implementaram políticas macroeconômicas com o objetivo de reduzir a atividade econômica, e desta forma controlar o aumento da inflação, os países sul-americanos, de uma forma geral, face a necessidade de legitimação dos regimes políticos não democráticos adotaram uma estratégia de maior endividamento externo como mecanismo de suprir a falta da poupança interna necessária para alavancar os projetos de desenvolvimento e crescimento

A resposta à crise fiscal e econômica por que passaram os primeiros governos pós-transição democráticos, nos anos I980 e I990, foi interposta por muitos através de medidas heterodoxas de cunho estruturalista, como congelamento de preços, controle do câmbio e aprofundamento da estratégia de substituição de importações, planos como o Cruzado (Brasil), Inti (Peru) e Austral (Argentina). O objetivo era conseguir a estabilidade macroeconômica sem recessão e assim fornecer "o apoio político necessário à implementação das reformas fiscais necessárias à estabilidade. Esta oportunidade foi perdi-

\footnotetext{
2 Available at http://estadisticas.cepal.org/cepalstat/WEB_CEPALSTAT/Portada.asp, accessed June 8, 2018.

3 Available at http://armstrade.sipri.org/armstrade/page/trade_register.php), accessed June 8, 2018 .
} 
da na Argentina, Brasil e Peru. A lua-de-mel inicial com o congelamento de preços foi confundida com sucesso e a consolidação fiscal foi evitada. Os programas então se perderam" (Cardoso I989, 40). O fracasso destas políticas heterodoxas, em muitos casos se materializou em situações de hiperinflação (taxas acima de 50\% ao mês) como na Argentina (I989), Brasil (I990), Peru (I988/1990). A Bolívia foi o caso mais extremo com I2.000\% de inflação no ano de I985. A média de inflação em I989 para a América Latina foi superior a mil por cento.

Depois dos fracassos das políticas de controle da economia heterodoxos, um novo conjunto de reformas, dentro da lógica das mudanças que ocorriam na estrutura do Welfare State dos países desenvolvidos, foram implementadas por novos governos latino americanos. Estas reformas genericamente conhecidas como "Consenso de Washington" preconizavam: I Disciplina fiscal rígida; 2 - Redução dos gastos públicos; 3 - Reforma fiscal e tributária; 4 - Abertura comercial; 5 - Taxa de câmbio livre; 6 - Liberalização do comércio exterior; 7 - Abertura para investimento estrangeiro; 8 - Privatização; 9 - desregulamentação da economia e flexibilização das relações e ıo - Proteção à propriedade intelectual. O "Consenso de Washington", apesar de ser visto por seus opositores como um receituário de reformas fixo, era percebido por seus defensores como um minimum minomorum. Cada país deveria implantar suas soluções de ajuste, a partir de suas realidades.

A Bolívia foi o primeiro país a adotar políticas de controle macroeconômico com forte conteúdo liberal. Em I985, o presidente Paz Estenssoro adotou um programa econômico pró-mercado denominado Nueva Política Económica (NPI), baseado nas ideias do economista Jeffrey Sachs. O programa de estabilização baseava-se em políticas fiscais e monetárias restritivas, abertura comercial, liberalização de preços e do câmbio, flexibilização do mercado de trabalho. A inflação caiu de estrondosos $23.000 \%$ para 10\% ao ano. O país apresentou uma recessão moderada em I986, depois teve vários anos caracterizado por baixas taxas de crescimento.

A Argentina em I99I, durante o governo Carlos Menem, adotou um modelo de ajuste (Plano de Conversibilidade) com fortes semelhanças ao implementado na Bolívia, como por exemplo: privatizações e uma política fiscal rígida. Contudo com uma diferença importante, o estabelecimento de um currency board (que obrigava o governo a lastrear toda emissão de moeda local, pelas reservas internacionais em dólar, no Banco Central), o que contrastava fortemente com o receituário de câmbio flutuante. "As taxas médias anuais de inflação foram reduzidas de $84 \%$, em I991 para 3,9\% em I994; durante o mesmo período de tempo o PIB cresceu a uma taxa anual média de 7,7\%, o consumo a uma taxa anual de $8,6 \%$ e o investimento real a uma taxa anual de 
22\%" (Wise 200I, I73).

Durante a década de I990, outros países como Equador, Venezuela, Brasil e Peru também adotaram planos de controle macroeconômicos, baseados em medidas pró-mercado como privatização, liberalização cambial, aumento de impostos e políticas fiscais restritivas. De forma geral, o resultado foi o mesmo, forte redução da inflação e estabilização macroeconômica.

Com a redemocratização, se intensifica o processo de integração econômica com a instituição de uniões alfandegárias. Forma-se o MERCOSUL com Brasil, Argentina e Uruguai, depois integra-se o Paraguai. O Pacto Andino, envolvendo Bolívia, Colômbia, Equador, Peru e Venezuela, se transforma em Comunidade Andina de Nações (CAN) e estabelece em I993, uma Zona de Livre Comércio (ZLC). Contudo, na área de defesa, a lógica da integração regional não tem qualquer efeito prático, ficando as relações entre as forças armadas dos países da região, centradas em pequenas manobras militares conjuntas, como as operações COLBRA (Colômbia/Brasil), VENBRA (Venezuela/Brasil) e Cruzeiro do Sul (CRUZEX).

Na última década do século XX, a maioria dos países que adotaram programas de estabilização econômica via medidas pró-mercado, com exceção do Chile, apresentavam como efeito colateral mais visível, o baixo crescimento da economia e o aumento da desigualdade. Em alguns casos, como na Bolívia e na Venezuela, as reações populares contra as medidas de austeridade econômica geraram revoltas populares importantes. Neste último, as manifestações sociais que ocorreram na capital Caracas, conhecida como Caracazo, pavimentaram a tentativa de golpe de estado em I992, comandada pelo coronel Hugo Chavéz.

Se a partir de meados dos anos 80 foram eleitos governos com programas econômicos pró-mercado, a partir do final da década começaram a ser eleitos governos com uma forte identificação com o ideário de esquerda e centro-esquerda. Hugo Chavéz em I998 foi eleito presidente da Venezuela, depois sucessivamente: Nestor Kirchner na Argentina (200I), Luís Inácio Lula da Silva no Brasil (2002), Evo Morales na Bolívia (2005), Tabaré Vázquez no Uruguai (2005), Michele Bachelet no Chile (2006)4, Rafael Correa no Equador (2007), Fernando Lugo no Paraguai (2008).

A "guinada 'esquerda" da América do Sul ocorreu ao mesmo tempo do "boom" de elevação dos preços das commodities no mercado internacional. Do início da década de 2000 até aproximadamente 2008 , o Brasil e outros países do subcontinente foram fortemente influenciados pela abundância de

4 No Chile, apesar da eleição de Michele Bachelet a política de compras de defesa não foi alterada. A preferência é por produtos fabricados no ocidente, preferencialmente os EUA. 
recursos trazidas pela alta internacional do preço de bens como petróleo, cobre, soja e minério de ferro. O crescimento da economia chinesa, em torno dos IO\% ao ano, foi um dos principais responsáveis por este fenômeno, conjuntamente com as baixas taxas de juros praticadas pelos países desenvolvidos.

\section{Gráfico 1 - Crescimento dos países da América do Sul - 2000 a 2010}

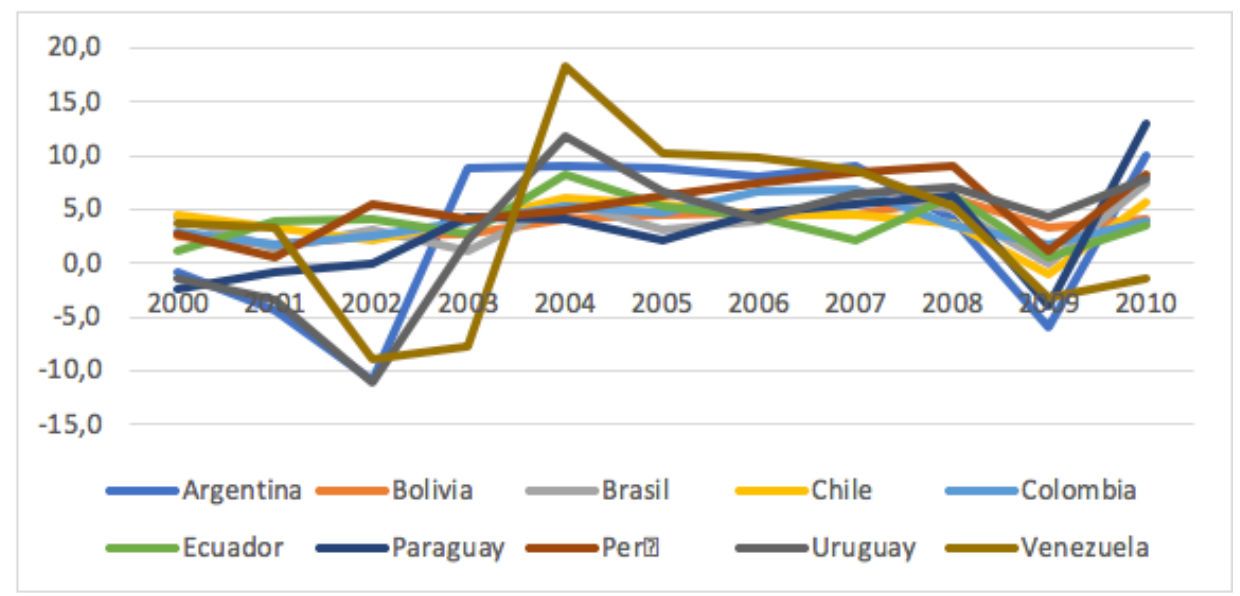

Fonte: CEPASTAT

O aumento do comércio mundial e a elevação dos preços da commodities produziram uma forte elevação do Produto Interno Bruto (PIB) das economias da América do Sul durante o período de 2000 a 2008, com variações importantes como as fortes quedas na atividade econômica ocorridas na Argentina, Uruguai e Venezuela em 2002. Contudo, de uma forma geral, as taxas de crescimento das economias do subcontinente foram significativas, com média em torno dos $4 \%$. O dinamismo das economias sul-americanas teve um impacto importante sobre a taxa de pobreza, que caiu de $44,5 \% \mathrm{em}$ 2000 para $33,0 \%(2008)$ e a renda per capita subiu de 3.886 dólares para 4.597. "O número de pobres e de indigentes existente em 2002, de 22I milhões e 97 milhões, respectivamente, reduziu-se para I80 milhões de pessoas pobres e 7I milhões de indigentes" (Prado 20II, I6)

A conjunção de governos de esquerda e o aumento da importância dos países emergentes, especialmente a China, preconizado pelo aumento do comércio sul-suls e a formação de fóruns de países como os conhecidos

5 “(...) de I995 a 2004, o montante movimentado pelo intercâmbio de mercadorias no eixo Sul-Sul passou de US\$ 222 bilhões para US\$ 562 bilhões. Em 2007, já respondia por

168 Austral: Revista Brasileira de Estratégia e Relações Internacionais v.7, n.14, Jul./Dez. 2018 
pelos acrônimos BRICS (Brasil, Rússia, China e África do Sul) e IBAS (Índia, Brasil e África do Sul) politicamente se materializou na formação de políticas externas mais independentes, quando não completamente adversárias das preconizadas em Washington.

Dentro do subcontinente sul-americano, a formação da União dos União Sul-Americana de Nações (UNASUL) e o Conselho de Defesa Sul-Americanos (CDS) são as principais consequências das políticas de integração sócio, política e econômica dos governos de esquerda à época, contudo deve ser destacado que a formação de organismos de integração remonta aos anos I980 e I990, como é o caso da Associação Latino-Americana de Integração (ALADI), Mercado Comum do Sul (MERCOSUL) e da Comunidade Andina de Nações (CAN). Mesmo que a ideia da formação de uma instituição que unisse politicamente os governos sul-americanos, em um fórum político para a resolução de problemas políticos e de segurança, remonte ao governo Fernando Henrique Cardoso em $2000^{6}$, um dos principais motivos para a cons-

I6,4\% dos US\$ I4 trilhões movimentados pelo comércio no mundo, cifra que, em 2000 , correspondia a II,5\%. O fluxo de investimentos estrangeiros diretos (IEDs) entre esses países também apresentou aumento: no mesmo período, estes passaram de US\$ I4 bilhões a US\$ 47 bilhões. As forças motrizes deste crescimento foram as grandes economias emergentes, mais precisamente, Brasil, Rússia, Índia e China - grupo de países conhecido pela sigla BRICS". Available at https://www.ictsd.org/bridges-news/pontes/news/comércio-sul-sul-no-contextoda-crise-econômica-oportunidades-e-desafios, acessado em Io de agosto de $20 \mathrm{OI}$

6 Em 2000, durante 32 ffi Assembleia Geral da OEA, o embaixador Osmar Chofli destacou as dificuldades da formação de uma política hemisférica de defesa. Contudo a formação de uma política subcontinental não era vista como completamente divergente de opções conjuntas como outros atores internacionais. "Acreditamos, contudo, ser difícil a convergência em tomo de uma concepção única e abrangente de segurança, plenamente aplicável às três massas continentais das Américas e ao Caribe. A América do Sul, continente no qual se insere geograficamente o Brasil, possui identidade estratégica própria. Distante dos principais eixos de tensão mundial, livre de armas nucleares e com baixos índices de despesas militares, os países sul-americanos conduzem um bem sucedido processo de integração regional, impulsionado pelo Mercosul e pela Comunidade Andina. A circunstância geográfica de uma mesma vizinhança imediata leva-nos a trabalhar em tomo de uma agenda comum de temas, oportunidades e preocupações. A democracia, a integração regional, nossa crescente comunhão de valores contribuem para que a América do Sul também se consolide como uma zona de paz, onde a cooperação e a busca conjunta da estabilidade e da prosperidade levaram à superação definitiva das rivalidades do passado, criando uma teia irreversível de interesses e oportunidades. Com todo o hemisfério mantemos posições convergentes em tormo dos grandes temas da agenda internacional, tais como, entre outros, a promoção e defesa da democracia, o respeito pelos direitos humanos, a proteção do meio ambiente, a superação da pobreza, o combate ao crime organizado e a nãoproliferação de armas de destruição em massa. Iniciativas subregionais e regionais não devem ser interpretadas como entraves à construção de uma perspectiva hemisférica de segurança. Ao contrário, constituem etapas importantes de reforço e complementaridade para arranjos de alcance hemisférico, pois facilitam, por meio de "building blocks", a identificação e a inclusão, no contexto geral, daqueles aspectos que podem ter aplicação comum. Available at http://www. 
tituição da UNASUL e do CDS foi a estratégia de alguns governos da região, especialmente Brasil, Argentina, Bolívia e Venezuela, de restringir institucionalmente os espaços de ação da Organização dos Estados Americanos (OEA) como um organismo de resolução de conflitos. A partir da UNASUL, os problemas sul-americanos não seriam tratados mais como interamericanos.

Do ponto de vista do Brasil, a criação do Conselho de Defesa Sul-Americano, em dezembro de 2008 , vincula-se ao objetivo de fortalecer a cooperação em temas de defesa e segurança e remete também à intenção de estabelecer um contraponto à penetração dos Estados Unidos na América do Sul, mais precisamente, na região andina. (...). Os países da região não tinham um histórico de cooperação no tema da segurança e defesa, muito por conta das diferentes leituras sobre os mesmos, e subordinavam a discussão dessas questões à relação com os Estados Unidos ou com os regimes e instituições criados à sombra da hegemonia desse país, como a Organização dos Estados Americanos (OEA). Com a formação do Conselho de Defesa Sul-Americana a ideia é utilizar a institucionalidade própria da Unasul para solucionar controvérsias e tensões na região, como ocorreu nos casos da crise institucional da Bolívia, em 2008 , da reação à utilização de bases militares dos Estados Unidos na Colômbia, da tensão entre Colômbia e Venezuela, em julho de 2oIo, e da deposição do presidente do Paraguai, Fernando Lugo, em junho de 2011 (Vigevani and Ramanzini Junior 20I4, 538).

\section{Mudanças Políticas e o Mercado de Defesa Sul-americano}

Como colocamos, a partir do início da primeira década do século XXI os países da América Latina viram uma profunda renovação nas lideranças políticas nacionais. Destas lideranças, a mais controvertida e mais carismática, certamente, foi o presidente o Hugo Chávez. Tenente-coronel reformado do Exército venezuelano, Chávez surgiu no cenário latino-americano como líder de uma tentativa de golpe militar contra o governo de Carlos Andrés Perez em I992. Preso, em face do fracasso da tentativa de golpe militar, Chávez é anistiado dois anos depois pelo presidente Rafael Caldeira. Em I997 cria um partido político, o Movimento da Quinta República (MVR), que um ano depois elege oito dos vinte e três governadores de estado e obtém I/3 das cadeiras no parlamento nacional. Seguindo sua trajetória meteórica como político, Chávez é eleito presidente em I998 com 56\% dos votos por uma coligação de partidos de esquerda. Aproveitando sua imensa popularidade, o presidente logo que assume convoca um referendo para uma nova Assembleia Consti-

oas.org/xxxiiga/english/speeches/speech_brasil.htm, acessado em Io de agosto de 2017 . 
tuinte, que obtém ampla aprovação. A coligação de apoio ao presidente venezuelano consegue eleger I2O dos I3I constituintes. A nova Constituição foi aprovada em referendo popular em dezembro de I999, e produziu profundas modificações nas regras do jogo político venezuelano: ampliou os poderes do executivo, permitiu uma maior intervenção do estado na economia, extinguiu o Senado e convocou novas eleições presidenciais em 2000, quando Chavéz foi novamente reeleito.

A política externa venezuelana, no início da década de 2000, tinha como objetivo tornar Hugo Chavéz o líder político mais importante da América Latina. Sua estratégia de ação possuía, pelo menos, três eixos: um vigoroso discurso em prol da unidade latino-americana contra a 'ameaça imperialista norte-americana'; apoio declarado a políticos de esquerda, em vários países do continente nos momentos de disputa presidencial; ajuda financeira a governos aliados e organizações políticas, inclusive de guerrilha.

Em ir abril de 2002 Hugo Chávez sofreu uma tentativa de golpe de estado. Militares rebeldes detiveram o presidente, extinguiram a Constituição, dissolveram a Assembleia Nacional e o Tribunal de Justiça e revogaram vários decretos e leis. Assumiu a presidência o empresário Fernando Francisco Carmona Estanga. O golpe durou menos de 48 horas. A oposição da população venezuelana, de facções militares, especialmente da Guarda Nacional, e de parte da Igreja Católica levou o golpe ao fracasso. Em todo o subcontinente, os governos da região denunciaram a interrupção da normalidade democrática no país. Contudo, o comportamento do governo dos Estados Unidos que não apenas não condenou o golpe, mas forneceu um reconhecimento implícito ao governo ilegal, desagradou a grande maioria dos países da região e abalou de forma profunda a já complicada relação entre a Venezuela e os EUA.

As relações entre as Forças Armadas Revolucionarias da Colômbia (FARC) e o governo venezuelano era um fato que produzia intensa instabilidade na região norte do subcontinente. A FARC é um grupo de guerrilha, atualmente em processo de desarmamento, de ideologia leninista-marxista, surgido em meados dos anos 60 que lutou contra todos os governos colombianos com o objetivo de instaurar um regime socialista no país 7 . O presiden-

7 Em 2004, como decorrência da consolidação de Hugo Chávez como líder da esquerda latino-americana, e do apoio deste a luta guerrilheira na Colômbia, a FARC também adota o bolivarianismo como ideologia política. Ricardo González, membro do Estado Maior da FARC, afirma que: "estamos también construyendo el Movimiento Bolivariano por la Nueva Colombia que es un movimiento también clandestino con fuerte arraigo en los sectores del estudiantado, entre los sectores obreros, en los barrios periféricos de las grandes ciudades, en los sectores universitarios y en la intelectualidad. Lo que pasa es que éste es un trabajo eminentemente clandestino y la gente no puede descubrir ante los demás lo que está haciendo desde el punto de vista de su trabajo ideológico, político, organizativo". Available at http://www.rebelion.org/ 
te venezuelano Hugo Chávez defendia que os países latino-americanos não deveriam classificar a guerrilha colombiana como terrorista, mas sim como "força de oposição beligerante" (a FARC é considerada uma organização terrorista pelo governo dos Estados Unidos, Canadá e a União Europeia).

As péssimas relações entre EUA e Venezuela passam a ser de atrito explícito quando os EUA, no inicio de 2006, impedem o governo de Hugo Chávez de ter acesso à tecnologia militar mais recente. Primeiro, impedindo a Força Aérea Venezuelana de reformar, através de uma modernização do tipo Mid-Life Update (MLU), seus velhos caças bombardeiros F-I6 Fighter Falcon (modelos A e B Block I5 que já eram obsoletos quando foram recebidos em I983). E depois, proibindo as empresas fabricantes de armamento de exportar qualquer equipamento com tecnologia norte-americana utilizando a legislação do Arms Export Control Act ${ }^{8}$. Brasil e Espanha foram impedidos de vender aviões de treinamento (A-29/Super Tucano) e de transporte (C-295) ${ }^{9}$ (Villa and Viggiano 20I2).

Foi neste pano de fundo político que a Venezuela inicia um forte processo de aquisição de material de defesa não ocidental. A política de aumento da capacidade militar da Venezuela se inicia com a compra em quantidades expressivas de material bélico russo, primeiramente com a aquisição de 24 caças Sukhoi - 30 MK2 Flanker, I00.000 fuzis de assalto AK-ı03 (e licença para fabricação) e 53 helicópteros da fabricante Vertolyoty Rossii, num total estimado de 3 bilhões de dólares (Oliker et al. 2009).

U.S. and regional officials fear that Venezuelan leader Hugo Chavez is seeking to foment revolution throughout Latin America and that he will use his new Russian- made arsenal for this purpose. Chavez's first target could be Colombia, where Venezuelan-made AK-47s might end up in the hands of the Colombian rebel groups such as the Revolutionary Armed Forces of Colombia and the National Liberation Army (Oliker et al. 2009, I82).

hemeroteca/plancolombia/040407urbano.htm, accessed June 8, 2018.

8 Available at https://www.pmddtc.state.gov/regulations_laws/aeca.html.

9 Villa e Viggiano $(2012,33)$ detalham que: “In 2006, the US State Department imposed an embargo that prevents Venezuela from importing goods and services of Defense nature. In the same year, Venezuela was certified by the US government, under Section 40A of the Arms and Control Act (AECA), as a country "not fully cooperative" in the fight against terrorism. The AECA certification was renewed in 2007 and 2008. By this mechanism, Venezuela is not allowed any assistance, sale or financing by the US military. In practice, the US embargo on arms sales has led representatives of the Venezuelan armed forces to pressure the executive to look for alternative import markets. Several arms-producing countries are alert to Venezuela's air force plans to buy other types of aircraft attached to the Sukhois purchased from Russia".

172 Austral: Revista Brasileira de Estratégia e Relações Internacionais v.7, n.14, Jul./Dez. 2018 
O processo de compra de armamento pela Venezuela tinha três objetivos; o primeiro reforçar sua política externa demonstrando total independência dos Estados Unidos, segundo ampliar e consolidar o apoio interno dos militares, essencial para o impedimento de novas tentativas de golpe de estado, e terceiro, modernização das forças armadas.

A aquisição de vultoso material de defesa produziu inquietação em várias lideranças políticas na América do Sul ${ }^{\mathrm{I}}$. A qualidade do equipamento militar dos países latino-americanos, especialmente os da região amazônica, à época era bastante inferior às necessidades dos países. Do final da década de 1990 e início do século XXI, a maioria das Forças Armadas estava com sua capacidade militar bastante reduzida, a Bolívia praticamente não possuía aviação militar (reduzida a poucos e antiquados jatos Lockheed T-33 Shooting Star) e suas forças terrestres eram completamente desaparelhadas e destreinadas. O Equador, que teve nos anos 90 uma força aérea capaz de rivalizar com a do Peru, encontrava-se quase que à beira da falência, reduzida a pouco mais de uma dezena de caças israelenses KFIR C2 e TC2. Seu exército, apesar de bem treinado, possuía poucas centenas de tanques leves AMX I3 com baixa disponibilidade. A Força Aérea Peruana era provavelmente a segunda mais poderosa do subcontinente, somente atrás da chilena (que havia comprado dezenas de caças F-I6 em 2002). Formalmente, a FAP possuia boa capacidade de combate com os seus MIG-29S Fulcrum e Mirage 2000 C/D, contudo não tinha condições financeiras de deixar todos os seus aviões em condições de operação ${ }^{\text {II }}$. O exército tinha como seus principais carros de combate antigos tanques T-54 e T-55 soviéticos. Com exceção da Colômbia, onde o governo recebia vultoso apoio material e financeiro dos EUA, na sua luta contra as Forças Armadas Revolucionárias da Colômbia (FARC), todas as outras instituições militares da região amazônica apresentavam sinais de franco declínio operacional.

Io Um exemplo é a entrevista do ex-presidente José Sarney: "a América do Sul é o mais pacífico dos continentes. Há mais de cem anos não temos uma guerra. A democracia está consolidada em toda a região. Nunca permitimos corrida armamentista. Ao menor sinal, todos reagimos". (...). Agora o plano de Chávez de gastar US\$ 60 bilhões em armas, transformando a Venezuela numa potência militar, é uma ameaça ao continente. (...). Para que tudo isso? Para enfrentar os Estados Unidos? Ora, para a superpotência isso não vale nada, mas para nós é uma força de fazer tremer. De duas uma: ou o Brasil entra na corrida armamentista para assegurar sua defesa, retirando o escasso dinheiro de seu Orçamento que está servindo para nossos programas sociais, ou então, para sobreviver, tem de acobertar-se no guarda-chuva da Otan, tragicamente fazendo voltar a tese de Menen, como única forma de defender-se. Menen era contra o Brasil, agora seremos todos unidos para nos defendermos da "nova potência militar" que dominará a América do Sul" (Folha de São Paulo, I4/07/2006).

II Available at http://larepublica.pe/amp/28-03-2005/los-aviones-de-fujimori-no-servianpara-atacar-ecuador, accessed June 8, 20I8 
O último ciclo de recomposição de equipamentos militares no continente sul-americano, ocorreu a partir dos primeiros anos de I970 até o início da década seguinte. Os países do subcontinente adquiriram equipamentos basicamente dos seus fornecedores clássicos: Estados Unidos, Inglaterra, Alemanha e França, sendo que o Peru deu preferência por armamento da União Soviética em vez dos norte americanos. Israel tornou-se um fornecedor importante de equipamentos de defesa: aviões (IAI Dagger e IAI AVARA), metralhadoras-compactas (UZI), bombas não-guiadas, sistemas eletrônicos de diversos tipos, mísseis ar-ar (Shifir e Python) e mar-mar (Gabriel) e lanchas torpedeiras (classe Sa'ar).

A compra de equipamentos militares é uma decisão política. Não há como desenvolver uma teoria geral sobre quais as razões motivam um país a adquirir mais equipamentos. As motivações podem ser classificadas, de forma geral, como internas (ligado por exemplo a proteção do regime, a busca de apoio político dos militares ou subsídios para a modernização da indústria de defesa) e/ou externas (ampliação da capacidade para se defender de uma agressão ou promover um, aumento da influência política regional ou mesmo hemisférica). No caso da América do Sul, a compra de aviões, tanques, metralhadoras e navios seguia a lógica política da guerra fria. No subcontinente, o primeiro país a comprar equipamentos militares soviéticos/russos foi o Peru. Em i968, o general Juan Velasco Alvarado derrubou o presidente Fernando Bellaúnde Terry e implantou uma administração nacionalista e de políticas reformistas de esquerda. As escolhas políticas do novo governo militar logo o colocaram em rota de colisão com Washington, como a nacionalização das empresas de petróleo (e posterior criação da estatal PetroPeru) e o aumento do mar territorial peruano para 200 milhas marítimas. As políticas sociais e econômicas do regime militar peruano e o estremecimento das relações com o EUA levaram a União Soviética dar apoio ao governo Velasco.

The Velasco regime's anti-imperialist rhetoric and its policies of economic nationalism drew praise and interest from Moscow. Soviet analysts viewed these policies as politically encouraging and capable of shifting the balance of power in favor of the Soviet Union. The Soviet Union gained significant goodwill after a devastating earthquake in the Callejón de Huaylas near Chimbote in northern Peru, killed seventy thousand people and left 500,000 homeless on 3I May 1970. Soviet medical teams gave valuable assistance to the injured and loaned Mi-8 helicopters to be used in relief efforts (Masterson I99I, 258).

O governo militar peruano, na tentativa de maior independência de Washington, e de recompensar a solidariedade dos governos dos países da 
Cortina de Ferro no terremoto de I970, passou a comprar material militar soviético. Em I973, o Peru comprou 36 caças Sukhoi-22 Fitter (já era operador desde 1968 dos caças Mirage 5 franceses), i6 aviões de transporte Antonov AN-26, 350 tanques T-54 e T-55, misseis antiaéreos SAM-3 e SAM-7, lança rojão RPG -7 e helicópteros MI-6 e MI-8, dentre outros equipamentos e assistência. Contudo, a compra de equipamentos militares foi restrita ao exército e força aérea, a marinha recusou o oferecimento de navios e submarinos russos preferindo navios de fabricação italiana (fragatas Lupo) e alemãs (submarinos IKL-209). De I973 a I985 as aquisições militares da URSS custaram mais de I.6 bilhões de dólares (Clayton i999).

Nos bancos de dados do Stockholm International Peace Reseach Institute (SIPRI) identificam-se poucas compras de material bélico soviético durante a década de I980 e de apenas dois compradores, Peru e Guiana (helicópteros, misseis e aviões ${ }^{\mathrm{I2}}$. Não obstante a crise econômica que atingiu o país, os governos peruanos, em face da necessidade da luta contra a guerrilha, continuaram a comprar equipamentos militares, especialmente para a força aérea. A ampliação do mercado de defesa para os produtos russos somente aconteceu após o fim da guerra fria. Argentina, Brasil, Colômbia, Equador, Uruguai e Venezuela passam a adquirir equipamentos tão diversos quanto aviões de treinamento e acrobacia Sukhoi-29AR, passando por mísseis do tipo MANPAD como os Igla até helicópteros de ataque.

A abertura do mercado sul americano, após o fim da guerra fria foi, um fato importante para a indústria militar russa que sofria uma grave crise, em face das dificuldades econômicas, com o debacle da União Soviética e o fim do Pacto de Varsóvia em i99i (Oliker et al. 2009). Para os países do subcontinente sul-americano, a compra de material vindo da Rússia, além de mais barato que o fabricado no ocidente, permitia aos países driblar as restrições à compra de material de defesa mais sofisticado tecnologicamente, como por exemplo no caso dos mísseis terra-ar Igla/SA-I8 e ar-ar do tipo Beyond Vision Range (BVR) R-77. Na tentativa de impedir perdas no market share do mercado sul-americano, o governo Bill Clinton em I997 revoga o ato Presidential Directive 13 (PD-I3), instaurado pelo presidente Jimmy Carter que praticamente proibia a transferência de armamento com alta tecnologia ${ }^{\mathrm{I}}$.

Until I995, U.S. defense contractors paid little attention to Latin America. In a good year, Latin American generals bought no more than \$I billion

I2 A Argentina comprou em I983 mísseis SAM-7 da Bulgária e do Peru. Em I970, a Guiana declarou-se uma república cooperativista com forte conteúdo socialista. Logo depois, o país passa a comprar helicópteros de transporte e morteiros de $\mathbf{2} 20 \mathrm{~mm}$.

I3 Available at https://fas.org/irp/offdocs/pd/pdi3.pdf, accessed June 8, 2 o 8. 
worth of weapons, small change as long as aerospace giants had hundreds of billions of dollars in aircraft sales to the Pentagon and the Middle East. But with the Defense Department shrinking weapons buys and Arab countries no longer placing large orders, the billion-dollar Latin American market suddenly looked attractive.

(...)

Getting the Pentagon to lobby for lifting the restraints was easy. Then Defense Secretary William Perry had met with Latin American generals, and was convinced their days of overthrowing governments was over. If the Pentagon was lucky, it might even be able to unload some of its older model F-I6s south of the border and use the proceeds to restock its air wings with newer versions of the Falcon. Industry executives and Perry aides began publicly plugging the idea of lifting the restrictions: the countries of Latin America save for Cuba were now democratic, their economies were rebounding, and the jets their air forces flew in many cases were I950s vintage, went the spiel. "We treat the Latins like children when we say they can't have new planes," says Joel Johnson, the Aerospace Industries Association's international vice president, implying that to have fully adult relations with other countries requires supplying them with sophisticated $\operatorname{armaments}^{\mathrm{I}}$.

A crise econômica e as políticas de restrição de gastos, que atingiu a América do Sul durante os anos I990, se traduziu em uma pequena redução dos gastos com defesa, que caiu de $2,2 \%$ para I, $8 \%$ em I999 em porcentagem do PIB $^{15}$. A pequena queda da despesa dos países sul-americanos também acontecia em termos mundiais, contudo por uma outra razão, o fim da guerra fria. A partir da queda do Muro de Berlim e durante toda a década, o gasto militar mundial desabou de $3,2 \%$ para $2, \mathrm{I} \%$ do PIB.

I4 Available at http://edition.cnn.com/ALLPOLITICS/ı997/04/07/time/arms.html, accessed June 8, 2018.

I5 Muitas vezes havia um claro desejo de compra de material russo, mas a incapacidade financeira inviabilizava o negócio. Informação sobre interesses brasileiros em helicópteros de ataques russos, em meados da década de I990 (Glinki and Nutenko I998 apud Zubelzú de Bacigalupo 2000). Esta compra somente ocorreu em 2010. 


\section{Gráfico 2 - Gastos com Defesa por Produto Interno Bruto (PIB)}

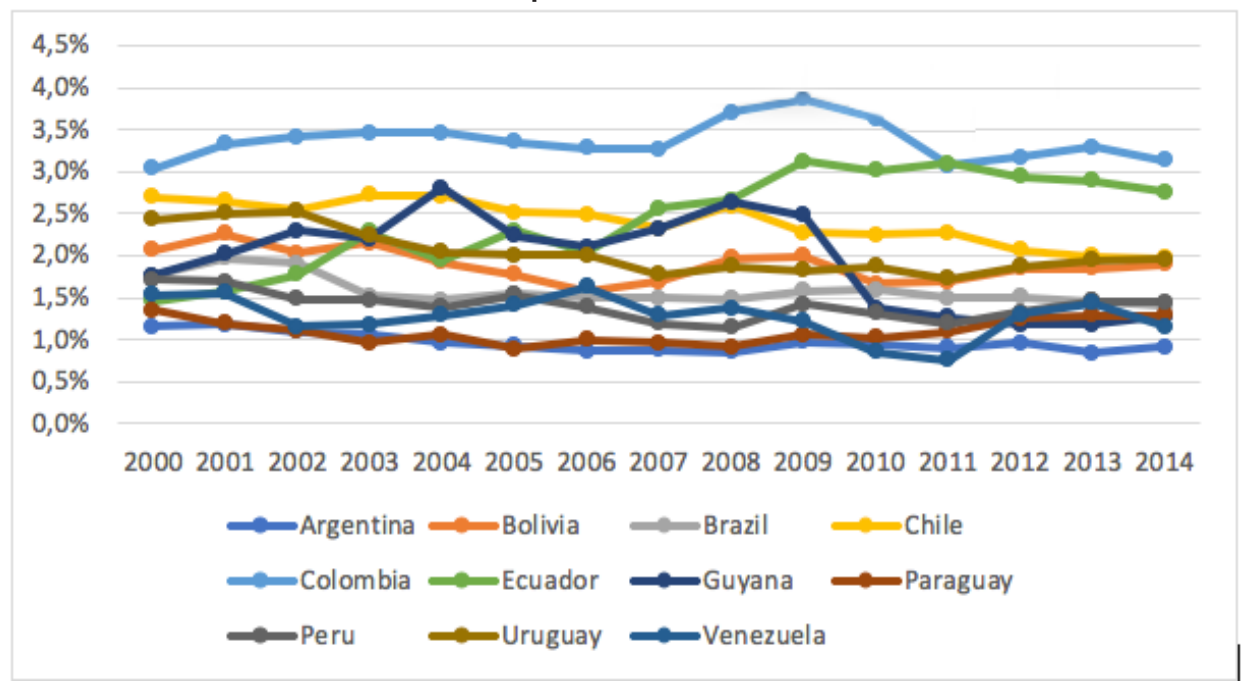

Fonte: SIPRI

O aumento do crescimento econômico dos anos 2000 veio acompanhado de uma recomposição e modernização dos arsenais militares dos países da América do Sul, especialmente Chile, Brasil, Colômbia, Equador, Peru e Venezuela. Destes casos, dois se destacam pelo seu forte conteúdo político, especialmente em relação à política externa norte-americana e a América do Sul. A Colômbia, em face dos investimentos norte-americanos com o Plano Colômbia (ajuda militar dos EUA com o duplo objetivo de reduzir a produção de cocaína e auxiliar as forças armadas colombianas contra os grupos guerrilheiros de esquerda), e a Venezuela com sua política de compra de armamento russo. $\mathrm{O}$ gasto com defesa no subcontinente era aproximadamente 24 bilhões de dólares no início do século, aumentou para 32 bilhões em $2007^{16}$, chegando a 57 bilhões em 2015 (SIPRI 20I6). Contudo, se observarmos este aumento em termos de porcentagem do PIB, perceberemos que o gasto com defesa caiu de 3,5 (1985) para I,9 (2002) e I,7 (2014).

I6 Dados retirados de Nueva Maioria - Balance Militar de América del Sul (2004) - http:// www.nuevamayoria.com/ES/BIBLIOTECA/?file=resenas/o4III6.html, accessed June 8, 2018. 


\section{Gráfico 3 - Gastos com Defesa por Renda Per Capita}

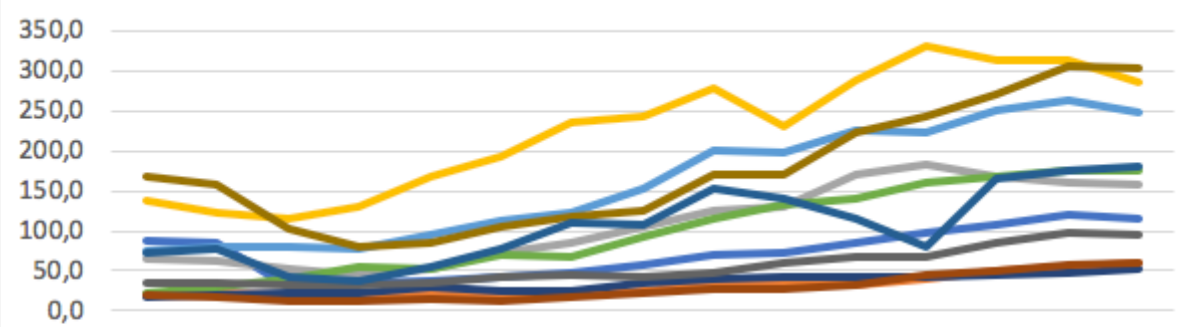

200020012002200320042005200620072008200920102011201220132014

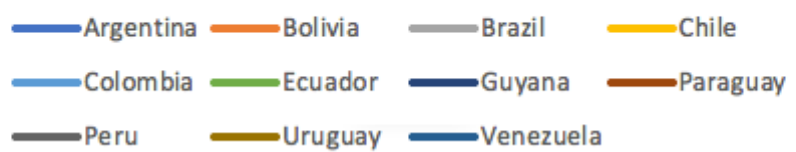

\section{Fonte: SIPRI}

Se a despesa com defesa, em termos de PIB, não teve elevação, per capita (dados de 2015) subiu de U\$3.674,00 (I985) para US 3.800,00 (2002) atingindo 6.25I dólares. Destaca-se o aumento dos gastos per capita do Chile, Uruguai, Equador e Colômbia. O baixo gasto em termos do Produto Interno Bruto dos países sul-americanos comparado com o aumento em termos per capita demonstra que o parte do forte crescimento econômico do período foi transformado em gastos com defesa.

O caso mais impressionante de aumento do gasto com defesa no período foi do Equador, cujo gasto aumenta de I,5\% do PIB para chegar ao máximo de 3,I nos anos de 2009 e 20II, caindo 0,03\% até 20I4. Em termos per capita, o aumento chegou a impressionantes $240 \%$.

En el marco del Consejo Suramericano de Defensa, la Unión de Naciones Suramericanas (Unasur) difundió el llamado Registro Suramericano de Gasto de Defensa. El documento develó que Ecuador es el país de la región que destina el mayor porcentaje del Producto Interno Bruto (PIB) al gasto militar: el 2,74\% en el 20I0. Colombia ocupa el I,89\%, mientras que Brasil el $0,77 \%$. En la cita efectuada ayer en Quito, la Unasur identificó cuatro objetos principales del gasto de Defensa. La mayor parte de la inversión en el área se ocupa en personal, seguida de recursos para operaciones y mantenimiento. En tercer lugar están las inversiones en armamento e infraestructura y finalmente la investigación ${ }^{17}$.

I7 Available at http://www.elcomercio.com/actualidad/seguridad/ecuador-destina-mayorporcentaje-del.html, accessed June 8, 2018.

178 Austral: Revista Brasileira de Estratégia e Relações Internacionais v.7, n.14, Jul./Dez. 2018 
De acordo com a empresa estatal de exportação de equipamentos de defesa da Rússia, Rosoboronexport ${ }^{18}$, o país exportou entre 200 I e 2017 mais de Io bilhões de dólares em equipamentos militares para os países da América Latina $^{\text {I9 }}$. Apesar do volume aparentemente alto, ele representa apenas $4,6 \%$ do volume total de armas russas exportadas ao mundo, cujo principal mercado é o asiático que representa 70\% (2000 - 20I6). A Venezuela é de longe o maior comprador latino-americano, representando $80 \%$ das vendas russas (Connolly and Sendstad 20I7). Além do regime bolivariano adquiriram, desde o início do século, equipamentos russos: Argentina, Bolívia, Brasil, Colômbia, Equador, Peru e Uruguai ${ }^{2 \circ}$. O Chile não possui nenhum equipamento de defesa fabricado na Rússia.

Venezuela e Peru são os países com maior número de equipamentos militares russos em seus inventários, os outros países do subcontinente adquiriram mais equipamentos norte-americanos e europeus, principalmente o Chile. A variedade das armas russas vendidas na América do Sul se concentra, especialmente em fuzis (AK), canhões de vários calibres, helicópteros de transporte e ataques (Mi-8MT/Mi-I7/Mi-35), mísseis (antiaéreos e antitanques) e veículos de transporte (BMP e BTR). Não existem nos dados no SIPRI informações sobre navios ou submarinos de fabricação russa incorporados por marinhas da América do Sul. Uma pesquisa nos sites das Armadas Venezuela e Peruana também não indicam a incorporação de belonaves russas. Interessantemente, os principais equipamentos navais das duas forças são bastante semelhantes, fragatas italianas, submarinos alemães e outros navios menores de várias procedências. A Venezuela realizou um acordo com Cuba, em 20I2, para a construção de navios de patrulha costeira (Damen Stan 2600) no país, através do estaleiro estatal $\operatorname{Ucocar}^{2 \mathrm{I}}$ e adquiriu oito navios de desembarque (Damen Stan Lander 56I2), construídos no Vietnã pelo estaleiro Ha Long Shipbuilding. Ambos, modelos de desenho holandês.

Aviões de fabricação russa voam sob as insígnias de várias das forças aéreas do subcontinente. Contudo, aeronaves nas funções de caça e bombardeio apenas nas de Peru e Venezuela. Suas situações de compra foram bastante distintas. Os Sukhoi-22 Fitter foram incorporados pela Força Aérea do Peru (FAP), nos anos I970, como parte de um acordo mais amplo de modernização das forças armadas. Em I996/8, os peruanos adquiriram, numa compra

I8 Available at http://roe.ru/eng/, accessed June 8, 2018.

I9 Available at https://br.rbth.com/defesa/20I7/04/24/america-latina-comprou-mais-de-usIo-bilhoes-em-armamentos-russos_74949I, accessed June 8, 2018.

20 Veículos de transporte BMP-I usados que foram comprados do Uruguai a Tchecoslováquia em meados dos anos 90.

2I Available at http://www.ucocar.gob.ve/ucocar_jo/ 
de oportunidade da Bielorrússia, I8 caças MiG-29 Fulcrum sem uma consulta prévia a Rússia. A compra gerou certa tensão entre as autoridades diplomáticas e militares em Moscou e Lima pela recusa da Mikoyan-Gurevich (MIG) em oferecer manutenção dos aviões, problema que foi superado pela compra pelo Peru de mais três MIG-29 diretamente da fabricante ${ }^{22}$.

No caso da Venezuela, já retratado antes, a compra se deu como uma resposta do governo Hugo Chavéz à proibição do governo dos EUA de acesso à tecnologia para a modernização e compra de equipamentos militares. No entanto, sempre houve um forte questionamento sobre a disponibilidade operacional dos Sukhoi - 30 Flanker MK2 ${ }^{23}$ na Aviação Militar Bolivariana (AMB).

(...) depois de 8 anos [20I4] de sua incorporação é pouco comum ver aos Su30 cumprindo funções de interceptação de aviões que incursionam no espaço aéreo Venezuelano, como nos incidentes com P-3 Orion Norte-americanos. Nestes casos, e também em interceptação de vôos vinculados ao narcotráfico, a aeronave despregada tem sido os já antigos F-I6 A/B Block I5 OCU.

Depois de alguns anos desde a incorporação dos Su-3oMK2, toda a frota teve que ficar em terra por três meses devido à falta de peças para sua operação. Nesse caso em particular foram itens que não são fabricados na Venezuela e que o provedor Russo demorou em encaminhar para a Venezuela. Nos rangos da Aviação Militar Venezuelana tem muita insatisfação em quanto o serviço ao cliente das empresas Russas, principalmente por ser um fornecimento não confiável e um inadequado apoio técnico. Este problema tem ofuscado as qualidades muito apreciadas do Su-3oMK2 na Venezuela, forçando a Aviação Militar Venezuelana de depender dos F-I6 como caça de primeira linha, ainda com os problemas de embargo que reduzem a frota de F-I6 e impedem sua modernização.

A incorporação dos Flankers na Venezuela trouxe muita esperança na Aviação Militar Venezuelana, mais o serviço pós-venda Russo tem trazido muitos problemas, e junto a uma média muito baixa de horas de voo mensais, o Flanker na Venezuela tem se convertido em um sistema pouco confiável criando um vácuo nas capacidades aéreas venezuelanas ${ }^{24}$.

A despeito dos problemas que podem ter ocorrido durante o processo de incorporação dos aviões de caça russos, o governo venezuelano na realidadem tem pouco espaço de manobra para a compra de aviões de combate de outros fabricantes, como no caso dos deltas europeus (Eurofighter Typhoon

22 Available at http://www.latinamericanstudies.org/peru/mig.htm, accessed June 8, 20 I8. 23 No Cruzex 20I3 a Aviação Militar Bolivariana (ABM) foi representada por quatro jatos F-I6. 24 Available at http://www.planobrazil.com/a-reduzida-operatividade-dos-sukhoisvenezuelanos/, accessed June 8, 2018.

180 Austral: Revista Brasileira de Estratégia e Relações Internacionais v.7, n.14, Jul./Dez. 2018 
ou JAS Gripen) ou mesmo caças chineses (J-10 ou J-I7). Em 2015, o presidente Nicólas Maduro anuncia a encomenda de mais I2 Sukhoi-3oMK2 para repor dois modelos perdidos em acidentes e abandonar completamente o uso dos F-I6 Fighting Falcon. O custo dos novos jatos foi estimado em quase meio bilhão de dólares.

A concentração das vendas russas à Venezuela e o aumento da competição com equipamentos militares de outros países têm obrigado a Rússia, a introduzir uma política de exportação de armamento mais agressiva na América Latina, especialmente em países que necessitam modernizar suas forças armadas e que são grandes exportadores de commodities, especialmente Peru, Equador e Argentina. Outro fato é a tentativa de adentrar em programas de modernização de equipamentos militares da era soviética, como o caso do T-55 peruano.

A China tem sido o grande parceiro comercial da América do Sul desde o início do século XXI. O dinamismo econômico chinês, traduzido durante vários anos em taxas de crescimento em torno de Io\%, refletiram no aumento das relações comerciais com os países do subcontinente. De 2000 a 2015 , a expansão comercial aumentou 22 vezes. De acordo com Holland e Barbi (20I0), as relações entre China e América Latina ocorrem de quatro formas: $\mathrm{I}^{\circ}$. Como importadora de recursos naturais e energia; $2^{\circ}$. Como exportadora de produtos industrializados, fabricados em território chinês, $3^{\circ}$. Pela formação de parcerias de tipo join-ventures ${ }^{25}$ e $^{\circ}$. Como fornecedora de empréstimos ${ }^{26}$.

A China em 2015 passou a ser o terceiro exportador de armas do mundo, apenas atrás dos Estados Unidos e da Rússia. Os maiores compradores de armas chinesas são Paquistão, Bangladesh e Myanmar, com quase 70\% do total (Fleurant et al. 20I7). Não obstante o aumento da importância das armas chinesas no comércio mundial, seu desenvolvimento guarda uma incógnita: qual o nível de desenvolvimento tecnológico do armamento chinês? A China aparentemente desenvolveu a estratégia de importar, de forma legal, armas de alta tecnologia para depois introduzir inovações com ajuda da espionagem

25 “Em 2008, a companhia estatal Petróleos de Venezuela (PDVSA) acertou uma joint venture com a China National Petroleum Corp (CNPC) para desenvolver o bloco 4 do campo de Junin no rio Orinoco. Neste projeto, a empresa chinesa terá 40\% de participação. Já a PetroChina firmou com a PDVSA uma joint venture para construir e operar uma refinaria com capacidade para 400 mil barris/dia retirados do poço de Junin 4. A PetroChina tem 60\% do projeto" (Holland and Barbi 2010, 22).

26 Em maio de 2009 “(...) o Banco de Desenvolvimento da China (CDB) emprestou US\$ Io bilhões para a Petrobrás. O acordo estabelece que a companhia exporteI5o mil barris de petróleo por dia à Unipec Asia, subsidiária da Sinopec, a companhia estatal de petróleo da China, a partir de 2009, e 200 mil barris por dia entre 2010 e 20I9" (Holland and Barbi 20I0, 22). 
industrial, como é o caso do Nanchang Q/A-5 Fantan (versão modernizada do Mig-I9 Farmer/Shenyang J-6, com um inteligente e bem-sucedido retrofit da entrada de ar e do randome do radar) e do Chengdu F-7 (cópia chinesa do Mig-2I Fishbed que era equipado com aviônica ocidental - radar Type 226 Skyranger da inglesa BAE System).

A partir de I950, a China passa a importar materiais de defesa da União Soviética e montar sob licença ou não, vários equipamentos que iam, desde o fuzil AK-47 (Norinco Type 56), passando por tanques como o T-54 (Norinco Type 59) e T-62 (Norinco Type 69) a diversos tipos de aviões. Em quase todos os casos, os chineses passaram a construir sob licença para, posteriormente, introduzir modificações até conseguir construir o equipamento com o máximo de componentes desenvolvidos no país. Com a abertura econômica das décadas de I980 e I990, e o boom do crescimento chinês nos anos 2000 , a China passou a receber e a investir mais em pesquisa tecnológica de defesa, mas sem abandonar sua estratégia clássica como demonstra o caso Sukhoi-27SK - Shenyang F/J-II ${ }^{27}$.

Se os chineses demonstram a probabilidade de alta capacidade de espionagem industrial (como por exemplo, nas fortes semelhanças de design entre o caça F-22 Raptor e drone MQ-9 Reaper dos EUA e seus congêneres J-20 e o CASC CH-5 Caihong), há um forte questionamento sobre a qualidade atual da produção de equipamentos chineses ${ }^{28}$. O caso IAI Lavi/Chendgu J-Io, a construção sob licença do helicóptero francês $\mathrm{AS}_{3}{ }_{6} 5$ Dauphin (Harbin Z-9), a utilização extensa de motores russos (Saturn AL-3I) nas principais aeronaves de combate, a utilização de motores ucranianos no principal tanque chinês (MTB2000) e nos aviões de treinamento avançado (Ko8 e L-I5), e a utilização de tecnologia ocidental nos sistemas de guia dos mísseis e outras tecnologias sensíveis ${ }^{29}$ demonstram que o país ainda não é capaz de produzir equipamentos militares de alta qualidade sem algum tipo ajuda externa ${ }^{30}$.

27 Available at https://sputniknews.com/russia/2008022199765686/, accessed June 8, 2018. 28 Available athttps://www.epochtimes.com.br/armas-da-china-real-guerra/\#.WcmS6ozOqu4 e https://dinamicaglobal.wordpress.com/2010/1о/16/a-china-conquista-o-mercado-de-armasmundial-trapaceando-com-material-de-ma-qualidade/, accessed June 8, 2018.

29 Available at http://www.newsweek.com/chinese-military-power-us-might-643022, accessed June 8, 2018.

$30 \mathrm{LiXiang}$ (20I3), ao analisar as dificuldades das forçar armadas chinesas com as transformações do século XII afirma que: "it is urgent to enhance the independent innovation of defenserelated science, technology, and industry. Scientific and technological progress is essential for implementing key information technologies, consequently improving the information level of weapons and equipment. However, there are still many problems to be solved in the national defense science and technology industry of China. For example, the structure is irrational; enterprise reform has not been deep enough; competition and capacity still need to improve;

182 Austral: Revista Brasileira de Estratégia e Relações Internacionais v.7, n.14, Jul./Dez. 2018 
“(...) China has made considerable headway in modernizing its defense science, technology, and industrial capabilities and has achieved impressive results in a number of areas since the turn of this century. Generational improvements have been made in the development and production of a growing array of weapons, from warships to combat aircraft, although the Chinese defense industry overall still lags technologically one or two generations behind the global frontier. Sharply increased funding for research and development, sustained high-level leadership attention, and the absorption of advanced foreign technologies, especially from Russia, are some of the major reasons for these gains" (Chase et al. 2015, 126).

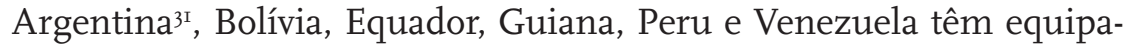
mentos militares de fabricação chinesa em seus arsenais. As primeiras armas foram compradas no início dos anos I990 pelos governos boliviano, equatoriano e peruano. Os dois primeiros adquiriram, basicamente, canhões e obuses (D20 e M30), mísseis portáteis tipo MANPADS (HN-5A) e mísseis antitanques (Red Arrow-8). O último comprou aviões de transporte leve Harbin Y-I2. Há um vácuo de quase io anos na compra de armas chinesas pelos países do subcontinente. A partir dos anos 2000 há um aumento significativo na compra de materiais de defesa de origem chinesa, tanto em termos de volume quanto de tecnologia embarcada. Argentina, Bolívia, Equador e Venezuela passam a adquirir diversos tipos de equipamentos que se destacam pelo grau de tecnologia empregada, como por exemplo blindados de infantaria (VNi6 e I8), radares de diversos tipos (JY-I, JY-II, YLC-I8, YLC-2), helicópteros (H-425 e Z-9), aviões de treinamento avançado (Honddu JL-8/K-8 Karakorum ${ }^{32}$, uma aeronave bastante semelhante ao jato inglês BAE Hawk) e o míssil ar-ar de curto alcance PL5E.

A compra de material bélico chinês parece ocorrer, principalmente, por questões de preço, eles são mais baratos que os ocidentais e russos, e políticos, os chineses não estabelecem qualquer restrição por causa do regime político do país. Um fato importante para o aumento das vendas têm sido o

and there is also a lack of strategic planning and institutional building of integrated militarycivilian development. These prominent contradictions should be solved in the second decade of this century" $(26-27)$.

3I A Argentina, além de comprar equipamentos militares chineses, adquiriu a licença para a fabricação do helicóptero ultraleve CZ-II, uma cópia do europeu AS 350B Ecureil.

32 A Bolívia tinha realizado um acordo com a fabricante de jatos tchecos Aero Vodochody para a compra de jatos de treinamento avançado L-I59 ALCA. Contudo, o governo norte-americano vetou a venda em face da utilização intensa de tecnologia dos EUA pelo avião tcheco, como por exemplo o motor Honeywell Fi24-GA-ıoo. Por esta razão, o governo de Evo Morales escolheu o jato K-8 que havia sido comprado pela Venezuela. Available at http://moraisvinna.blogspot. com.br/2009/08/chance-para-os-l-15-ou-yak-I3o-eua-nao.html, accessed June 8, 2018. 
oferecimento de financiamento via bancos estatais, principalmente o China Export and Credit Insurance Corporation (Sinosure) e o Export-Import Bank of China (China Exim Bank) ${ }^{33}$, para a compra destes materiais ${ }^{34}$. Um fato a ser destacado é que os principais compradores de armas chinesas, no subcontinente, são todos países com fortes governos de esquerda. Neste caso além do financiamento chinês, e provável que os governos estejam buscando escapar da dependência do fornecido de armamento russo, especialmente no caso da Venezuela.

Da mesma forma que acontece com equipamentos de defesa russo, não encontramos nenhuma referência à compra de países sul-americanos de navios ou submarinos fabricados ou que usem tecnologia chinesa. Apesar de países como Venezuela e Uruguai terem demonstrado interesse em adquirir navios de patrulha oceânico derivados do modelo P-I8N, uma provável razão do desinteresse sejam os poucos contatos entre as marinhas da América do Sul e do Exército Popular da China, como a que ocorreu em 2013, quando uma pequena flotilha chinesa composta pelo contratorpedeiro Lanzhou (Type $05_{2} \mathrm{C}$ ) e a fragata Liuzhou (Type 054A), participaram de manobras com a Armada chilena e a Marinha brasileira. Apesar de terem um excelente desenho furtivo, os novos navios chineses usam intensa tecnologia russa.

Com respeito a navios de treinamento e outros tipos de navios de guerra, a primeira dessas visitas foi feita pelo navio de treinamento da Marinha chilena, Esmeralda, ao Porto de Xangai em I972. Até 2009, Esmeralda havia visitado os portos chineses em Io ocasiões distintas. Em reciprocidade, a primeira flotilha naval da China visitou a América Latina em abril de I997. Incluía os contratorpedeiros (misseis) Harbin e Zhuhai e o navio de logística Nancang. A flotilha atracou no México, Peru e Chile, bem como na Base norte americana de Pearl Harbor. A visita mais recente desse tipo, no momento em que este artigo estava sendo redigido ocorreu em 2009 uma flotilha naval da China que incluía o contratorpedeiro Shijiazhuang e o navio de abastecimento Hongzehu atracou em Valparaíso, Chile, Callao, Peru e Guayaquil, Equador. Apesar de caráter pacífico, tais visitas beneficiam a Marinha do PLA, ajudando-a a identificar os requisitos para o futuro uso de portos latino-americanos para manutenção, reabastecimento e outros fins (Evans 20I2, 32).

Além do gigante asiático, outros países asiáticos estão tentando aden-

33 Available at https://www.bloomberg.com/news/articles/2013-07-I7/china-s-easy-moneyflows-abroad-as-credit-squeeze-hurts-at-home, accessed June 8, 20 I8.

34 A partir de 2013, a China também doou equipamentos militares para o Equador, Bolívia, Guiana, Colômbia e o Peru.

184 Austral: Revista Brasileira de Estratégia e Relações Internacionais v.7, n.14, Jul./Dez. 2018 
trar no mercado de defesa do subcontinente. A partir de 2012, a Coreia do Sul surgiu como um novo ator no comércio de equipamentos de defesa sul-americanos ${ }^{35}$. Colômbia e Peru têm sido os primeiros compradores de Seul. A estratégia sul-coreana se assemelha, em parte, a estratégia chinesa e de outros países, doação de equipamentos usados e posterior venda de novos ${ }^{36}$. Os coreanos doaram às marinhas peruana e colombiana antigas corvetas, para o primeiro da classe Pohang e para a segunda da classe Donghae. Como consequência das negociações os coreanos também estabeleceram join-ventures entre a companhia STX e as empresas COTEMAR (Colômbia) e SIMA (Peru) para a construção, transferência de tecnologia e desenvolvimento de novos modelos de navios de patrulha costeiros. Os peruanos construirão I4 e os colombianos 16 patrulheiras.

A estratégia coreana já foi utilizada para a entrada do país em outros mercados de defesa, especialmente o asiático dominado por EUA, Rússia e China. A partir de 2000 , o governo sul-coreano doou para Filipinas, Cazaquistão, Bangladesh, Gana, Timor Leste e Trinidad Tobago vários navios de patrulha da classe Chamsuri. Estas doações permitiram negociações para a posterior venda de outros equipamentos como aviões de treinamento avançado/ ataque KAI T-50, navios de desembarque e compra de corvetas para Filipinas (que comprou por ioo dólares uma corveta da classe Pohang), fuzis e metralhadoras fabricadas pela Daewoo para a Marinha de Bangladesh, munição de vários tipos para as Forças de Defesa do Timor-Leste.

As principais vendas da Coréia do Sul no mercado do subcontinente sul-americano foram vinte aviões de instrução básica KAI KT-I para a força aérea peruana, com transferência de tecnologia, modernização de instalações de montagem dos aviões e desenvolvimento de um simulador de voo específico. Dois navios de desembarque de fuzileiros (Classe Makassar) construídos no país. Dezesseis mísseis anti-navio C-Star SSM-70oK para a marinha colombiana para substituir os mísseis franceses Exocet.

35 Anteriormente, o país havia vendido equipamentos menos sofisticados. "Korean Aerospace Industries aims to expand its market in South America as well. Since 2006, Latin American countries have imported $\$ 48.9$ million worth of ROK defense gear including trucks, flak vests, ammunition, and communication devices". Available at http://www.sldinfo.com/the-evolutionof-south-korean-defense-industry-an-emerging-global-player/\#_ftn6o, accessed June 8, 2018.

36 Available at http://www.idsa.in/idsacomments/decommissioned-military-hardware sbmaharaj_iooıI7, accessed June 8, 20 I8. 


\section{Conclusão}

O objetivo deste texto é discutir como as alterações políticas, ocorridas na América do Sul nos primeiros anos do século XXI, influenciaram a compra de equipamentos militares modernos por alguns países do sul-americanos. Profundas mudanças econômicas e políticas ocorreram no subcontinente. Governos de perspectiva política de esquerda dos mais variados graus assumiram o poder, ao mesmo tempo, que havia um aumento expressivo nas taxas de crescimento das economias dos países em desenvolvimento. $\mathrm{O}$ aumento do preço das commodities alavancou tanto programas de bem-estar social como a compra de equipamentos de defesa.

A compra de materiais de defesa é uma decisão política. As motivações para um país adquirir material de defesa são tanto derivadas de questões internas (como a natureza do regime político) quanto externas (possibilidade de conflito). Guiana em I968 e o Peru em I973 começam a adquirir armamento russo, como decorrência da aproximação política com Moscou, em detrimento de equipamento militar dos EUA. Mesmo findo a guerra fria, os peruanos continuam a dar preferência a aviões de fabricação russa. Outros países passam a adquirir outros equipamentos não fornecidos pelos EUA, ou que eram passíveis de veto, como os mísseis Igla-S comprados pelo Brasil em meados dos anos I990.

A Venezuela é certamente o caso mais emblemático. As posições políticas do presidente Hugo Chavéz o colocaram em rota de colisão direta com Washington. As administrações George Bush e Barack Obama bloqueiam as tentativas de Caracas de modernizar equipamentos de origem dos EUA e estabelecem vetos à venda de outros materiais com sua tecnologia norte-americana, produzidos por europeus ou pelo Brasil. O resultado foi que o governo venezuelano institui uma política de compra expressiva de armamento, vindo de Moscou. Posteriormente, a China também passa a ser uma fornecedora preferencial junto com Cuba e Vietnã. A decisão do governo venezuelano também tem forte influência sobre as compras de equipamentos de defesa, feitas pela Bolívia, que também sofre veto dos EUA.

A maior ameaça à venda de equipamentos russos para a região parece vir da China. Com o aumento das relações econômicas e políticas derivadas da expansão da chinesa. Pequim passa a investir na venda de equipamentos militares através do financiamento, via bancos estatais, a vários governos. Equatorianos, bolivianos, venezuelanos e argentinos passam a comprar equipamentos chineses dos mais variados tipos, de canhões a aviões de treinamento avançado. 
Um outro competidor importante que adentra no mercado sul-americano é a Coréia do Sul. Com uma já testada estratégia de venda em outros países (doação de navios e posterior oferecimento de produtos) tem atraído países sul-americanos que querem diversificar seus fornecedores com equipamentos de alta tecnologia como: aviões, navios e mísseis.

\section{REFERÊNCIAS}

Cardoso, Eliana. I989. Hiperinflação na América Latina. Revista de Economia Política 9 (3): 2I - 4I.

Chase, Michael et al. 20I5. "China's Incomplete Military Transformation: assessing the weakness of the People's Liberation Army (PLA): . Santa Monica: Rand Corporation. Accessed August Io, 20I7. http:// www. rand.org/t/RR893.

Clayton, Lawrence. I999. Peru And The United States: the condor and the eagle. Athens: University Georgia Press.

Connolly, Richard and Cecilie Sendstad. 20I7. "Russia's Role as an Arms Exporter: the strategic and economic importance of arms exports for Russia”. London, The Royal Institute of International Affaris. Accessed June o6, 2018. https://www.chathamhouse.org/sites/files/ chathamhouse/publications/research/20I7-03-20-russia-arms-exporter-connolly-sendstad.pdf.

Evans, R. Evans. 20I2, "Engajamento Militar China - América Latina; boas intenções, bom negócio e boa posição estratégica". Air \& Space Power Journal 24 (3): 22 - 47. Accessed June o6, 2018. http://www.au.af. $\mathrm{mil} / \mathrm{au} / \mathrm{afri} / \mathrm{aspj} /$ apjinternational/apj-p/20I2/20I2-3/20I2_3.pdf.

Fleurant, Aude et al. 20I7. "Trends in International Arms Transfers, 2016". SIPRI Fact Sheet. February 2017. Accessed June o6, 20I8. https:// www.sipri.org/sites/default/files/Trends-in-international-arms-transfers-20i6.pdf.

Gilkin, Anatoly e Leonid Nutenko. I998. "Parámetros Básicos de un modelo de relaciones de socios”. Revista Iberoamericana. Instituto de América Latina, no. 02.

Holland, Marcio and Fernando Barbi. 20ıo. "China na América Latina: uma perspectiva dos investimentos estrangeiros diretos". São Paulo: FGV/ EESP (Textos de discussão). Accessed June o6, 2018. http://bibliotecadigital.fgv.br/dspace/bitstream/handle/I0438/425I/TD\%20 
247\%20-\%20Márcio\%2oHolland\%3b\%2oFernando\%2oBarbi.pdf? sequence $=I \&$ isAllowed $=\mathrm{y}$.

Masterson, Daniel. I991. Militarism and Politics in Latin America: Peru from Sanchez Cerro to Sendero Luminoso. Westport: Greenwood.

Oliker, Olga et al. 2009. Santa Monica: Rand Corporation.

Prado, Antonio. 20Ir. "O Desenvolvimento na América Latina Depois da Crise Financeira de 2008". Revista Tempo do Mundo 3 (3): 9-27. Accessed June 6, 20I8. http://repositorio.ipea.gov.br/bitstream/II058/6228/I/ RTM_v3_n3_Desenvolvimento.pdf .

Stockholm International Peace research Institute (SIPRI). 20I6. "SIPRI Yearbook 20I6: armaments, disarmament and international security - summary". Accessed June 6, 20I8. https://www.sipri.org/sites/ default/files/YBi6-Summary-ENG.pdf .

Vigevani, Tullo and Haroldo Ramanzini Junior. 20I4. "Autonomia, Integração Regional e Política Externa Brasileira: Mercosul e Unasul”. Dados Revista de Ciências Sociais 57 (2): 517-552.

Villa, Rafael Duarte and Juliana Viggiano. 2012. "Trends in South America Weapons purchases at the beginning of the new millennium". Revista Brasileira de Política Internacional 55 (2): 28 - 47.

Wise, Carol. 200ı. "Currency Board da Argentina: os laços que unem?". Revista de Economia Política 2I (3) : I68-I94.

Xiang, Li. 2013. "Military Transformation with Chinese Characteristics in the New Century.” Institute for Security \& Development Policy. Asian Paper. Accessed June 6, 20I8. http://isdp.eu/content/uploads/images/ stories/isdp-main-pdf/20I3-xiang-military-transformation.pdf .

Zubelzú de Bacigalupo, Graciela. 2000. "Relações bilaterais soviético-brasileiras”. Revista Brasileira de Política Internacional 43 (2): 59-86. 


\section{RESUMO}

O artigo busca discutir se o impacto das mudanças políticas, ocorridas na América do Sul a partir da primeira de década do século, influenciou a compra de equipamentos militares por alguns países da região. O surgimento de novos governos, com forte inclinação à esquerda, ocorreu concomitantemente com uma clara mudança no padrão clássico de compra de equipamentos de defesa. Países europeus e os EUA passaram a ser preteridos, em contraponto a Rússia e China, como fornecedores de armamentos para as várias forças armadas sul-americanas.

\section{PALAVRAS-CHAVE}

Política, defesa, Rússia, China, Coreia do Sul

Traduzido por Fernanda Gomes Carvalho 